\title{
Arquiteturas Pedagógicas para a Educação a Distância: a construção e validação de um objeto de aprendizagem
}

\author{
Prof $^{a}$ Dr $^{\mathrm{a}}$ Patricia Alejandra Behar - UFRGS- pbehar@terra.com.br \\ Ms. Maira Bernardi - UFRGS - mairaber@terra.com.br \\ Ketia Kellen Araújo da Silva - UFRGS - ketiakellen@gmail.com
}

\begin{abstract}
Resumo: O ARQUEAD é um OA sobre Arquiteturas Pedagógicas para a Educação a Distância (EAD). Este objeto foi construído no intuito de oportunizar, através do material digital, novas experiências aos professores sobre as arquiteturas pedagógicas sob uma abordagem interacionista. Sua utilização é destinada a situações de aprendizagem tanto na modalidade à distância como na presencial. O principal objetivo do ARQUEAD é possibilitar aos seus usuários um aprofundamento de conhecimentos teórico-práticos sobre a temática Arquiteturas Pedagógicas para EAD. Este objeto foi validado através de um curso de extensão desenvolvido na Universidade Federal do Rio Grande do Sul.
\end{abstract}

Palavras Chave: Arquiteturas Pedagógicas, Objetos de Aprendizagem, Educação a distância

\section{Architectures Education for Distance Education: the construction and validation of a learning object}

\begin{abstract}
The ARQUEAD is a learning object about Architectures on Education for Distance Education (EAD). This object was constructed in order to be possible through digital material, new experiences for teachers on teaching architectures under an interactionist. Its use is for situations of learning both in distance mode and in presence. The essential objective of ARQUEAD is allowing its users to a deeper theoretical and practical knowledge on the theme Architectures Education. This object was validated through a process of extension developed at the Federal University of Rio Grande do Sul.
\end{abstract}

Key words: Architectures Education, Objects of Learning, Distance education.

\section{Introdução}

O presente artigo trata de uma reflexão acerca dos referenciais teóricos do objeto de aprendizagem (OA) ARQUEAD, suas etapas de construção e sua aplicação para testes e validação em um curso de extensão. Este é um objeto sobre Arquiteturas Pedagógicas (APs) para a Educação a Distância (EAD), projetado por uma equipe interdisciplinar do Núcleo de Tecnologia Digital aplicada à Educação (NUTED) da UFRGS. Na construção do 
ARQUEAD, procurou-se atender aos requisitos tecnológicos, epistemológicos, metodológicos e de design pedagógico. O objetivo da validação através da sua aplicação em um curso de extensão procurou verificar a qualidade dos recursos e referenciais do objeto em relação a estes requisitos. A escolha do curso na modalidade extensiva foi pela possibilidade de focar o tema do objeto, realizar atividades prático-reflexivas, nas quais os participantes puderam trabalhar com as temáticas relacionadas ao assunto proposto, obtendo uma fundamentação teórica sobre as arquiteturas pedagógicas.

O objeto de aprendizagem ARQUEAD faz parte do projeto Arquitetando a Educação a Distância, fomentado pela Secretaria de Educação a Distância (SEAD) da Universidade Federal do Rio Grande do Sul (UFRGS). O objetivo da presente proposta é abordar as diferentes correntes pedagógicas (epistemológicas), a utilização de funcionalidades, recursos e ferramentas de ambientes virtuais de aprendizagem (AVAs). Isto de acordo com a metodologia do professor, o conteúdo trabalhado e a construção das APs resultantes desta combinação, ou seja, a prática pedagógica em EAD. Para garantir a reutilização do objeto, o ARQUEAD foi classificado dentro do padrão de metadados, com a descrição das informações do objeto, sob diferentes suportes documentais.

Nesta abordagem, compreende-se que os OAs favorecem uma nova concepção de aprendizagem, apoiada por computador, a qual se caracteriza por promover a construção de conhecimento através da interação. Portanto, acredita-se que o sujeito deva exercer um papel ativo frente a sua aprendizagem, apoiado por objetos que permitem a sua atuação e reflexão sobre os conteúdos trabalhados.

\section{Arquiteturas Pedagógicas: um caminho a construir}

A compreensão, na área educacional, acerca da expressão "arquiteturas pedagógicas" (AP) tem trazido múltiplas interpretações, sendo que estas estão diretamente relacionadas com uma linha epistemológica que dá embasamento para sua proposta pedagógica.

Neste estudo, parte-se da definição utilizada por Behar (2009), que considera Arquitetura Pedagógica (AP) como "um sistema de premissas teóricas que representa, explica e orienta a forma como se aborda o currículo e que se concretiza nas práticas pedagógicas e nas interações professor-aluno-objeto de estudo/conhecimento". Assim, a AP é constituída por um gama de elementos organizacionais, instrucionais, metodológicos e tecnológicos, os quais mantêm uma inter-relação. As relações entre os elementos que compõem a AP e que dão seu real significado podem ser representadas pela imagem do encaixe de peças de um quebra-cabeça como mostrado na figura 1. 

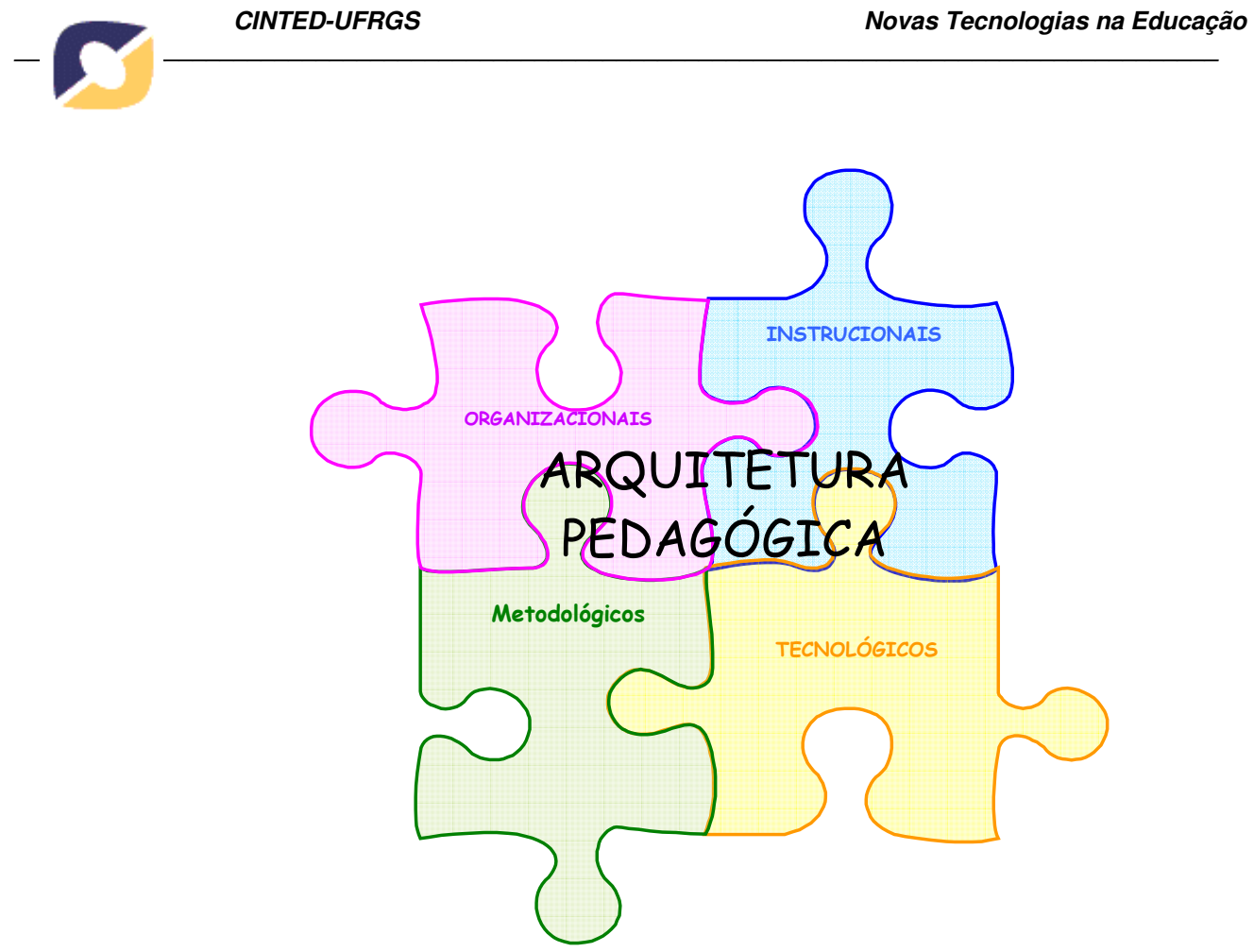

Figura 1: Conjunto de elementos de uma Arquitetura Pedagógica

Dentre os elementos organizacionais da arquitetura pedagógica (AP), estão todos aqueles intrinsecamente envolvidos na elaboração da proposta pedagógica e sua culminância. Destacam-se os objetivos e finalidades da aprendizagem a distância, a compreensão do tempo e do espaço (neste caso pautados na perspectiva da virtualidade), os perfis dos sujeitos envolvidos no processo - o aluno, tutor e professor, bem como a definição das suas competências e habilidades (Behar, 2009).

Os aspectos organizacionais precisam estar em consonância com o Projeto Político Pedagógico da EAD e o Plano de Desenvolvimento Institucional no nível macro e com o Projeto Pedagógico de Curso no nível micro e os demais pressupostos que integram a gestão da EAD. Com a articulação dos planejamentos e de suas propostas será mais viável atender aos objetivos traçados.

Os aspectos instrucionais estão relacionados, como enfatiza Behar (2009), "ao 'o quê' será trabalhado". Com relação aos elementos instrucionais, estão sendo considerados todas as formas e formatos (impresso, digitalizado, imagético,...) da proposição dos conteúdos de ensino. Estes podem ser disponibilizados através de recursos informáticos (como objetos de aprendizagem, softwares educativos ou mesmo páginas web, hipertextos) e demais ferramentas de aprendizagem, de forma isolada ou agregada. Independe-se o tipo de conteúdo que se queira trabalhar, seja este conceitual, fatual, atitudinal, ou procedimental, conforme a interpretação de Zabala (1999).

Esse conjunto de elementos deve ser cuidadosamente definido, para que, a partir deles, seja possível construir conhecimento e desenvolver capacidades. Vislumbra-se, assim, a importância do processo de seleção de conteúdo, com destaque para a construção de objetos de aprendizagem, a fim de estes serem trabalhados com motivação e interesse na proposta pedagógica como um todo.

Dentre os aspectos metodológicos constituintes de uma AP, estão as atividades, as formas de interação/comunicação a serem utilizadas, os procedimentos de avaliação adotados e a organização desse conjunto de elementos numa determinada ordenação. 
Portanto, não se trata somente da seleção das técnicas, procedimentos e dos recursos informáticos a serem utilizados na aula, mas de articular e estruturar a proposta pedagógica anteriormente elaborada, combinando os elementos para o alcance dos objetivos almejados. Logo, compreende-se que esta ordenação e as relações constituídas podem vir a determinar as características da intervenção pedagógica. A ordenação do conjunto de elementos é determinada por Zabala (1999) como seqüência didática ou de atividades. Desta forma percebe-se que a elaboração, seleção e organização dos elementos metodológicos estão intimamente relacionados aos pressupostos didáticos definidos para a aplicação do projeto pedagógico de curso e, conseqüentemente, de suas disciplinas. Como já foi apontado, de acordo com a legislação que respalda as práticas da EAD, a avaliação precisa contemplar uma atividade final realizada presencialmente.

E, finalmente, como elementos tecnológicos, estão inseridos a definição da plataforma tecnológica e suas funcionalidades, bem como recursos destinados à promoção da comunicação (síncrona e/ou assíncrona), como a videoconferência (Behar, 2007; 2009). Estes ambientes virtuais de aprendizagem (AVAs) são propostos para fornecer suporte aos processos de ensino-aprendizagem na modalidade EAD. Ressalta-se, entretanto, que cada ambiente foi construído tendo como premissa implícita ou explícita uma ou mais concepções de aprendizagem. É importante observar se a plataforma a ser selecionada corrobora a proposta pedagógica adotada, atendendo as características do curso e das disciplinas.

A partir da definição e dos elementos da arquitetura pedagógica respaldada na concepção de Behar (2009), muitos são os fatores que estão comprometidos com a realização de um curso a distância. Cada um destes precisa ser compreendido e muito bem definido pelos gestores e professores, para que sejam atendidas as necessidades do curso e para a construção do modelo pedagógico de EAD almejado.

$\mathrm{Na}$ opinião da autora, em grande parte dos cursos desenvolvidos na modalidade EAD, é adotada oficialmente uma AP, formado por uma proposta de planejamento, contemplando, também, a pré-definição de conteúdos e demais aspectos metodológicos e tecnológicos, numa atitude incisiva por parte da instituição. Esta acaba por repercutir numa base de diretrizes gerais para que os professores articulem seus trabalhos (Behar, 2009). Entretanto, o diferencial está nas possibilidades de aplicação de uma AP quando são considerados os fatores relacionados aos aspectos sociais, emocionais e pessoais determinantes pelo público-alvo do curso na modalidade a distância e os demais sujeitos envolvidos na sua aplicação, ou seja, gestores, professores e tutores.

\section{Objeto de aprendizagem ARQUEAD - concepção e construção}

Neste estudo, Objeto de Aprendizagem (OA) é compreendido como qualquer material ou recurso digital (por exemplo: textos, animação, vídeos, imagens, aplicações, páginas Web, etc.) apresentado isoladamente ou em agregação, tendo uma finalidade educativa. (Willey, 2008). Logo, um OA é constituído de recursos autônomos, sendo estes reunidos em módulos tratando de um conteúdo determinado ou abordando uma temática em sua amplitude, em diferentes perspectivas. Tratam-se, pois, de materiais voltados para o desenvolvimento de situações de aprendizagem na modalidade EAD, semi ou totalmente presencial. 
Para a construção do ARQUEAD, foi utilizada a metodologia de construção de objetos de aprendizagem de Amante \& Morgado (2001), em quatro etapas: Concepção do Projeto, Planificação, Implementação e Avaliação.

Seguindo estes passos, a construção deste objeto foi iniciada pela concepção do projeto, através do cumprimento das etapas de definição das linhas mestras e apontamentos dos objetivos para o objeto.

A equipe foi definida de acordo com as necessidades expostas pelos objetivos elaborados. O grupo interdisciplinar foi composto por quatro educadoras, responsáveis pelo planejamento do projeto do ARQUEAD e dois designers para a implementação da sua interface.

Neste primeiro momento foi, também, caracterizado o público-alvo para o objeto: professores e tutores, atuantes em cursos nas modalidades presencial, semipresencial e a distância. Assim, foi possível delimitar os conteúdos e os principais objetivos que se pretendia desenvolver no ARQUEAD.

Na sequiência, partiu-se para a fase de planificação do objeto. A primeira etapa foi a realização do estudo do storyboard e da navegação, devido à sua estrutura não-linear. A seguir, foram definidos os tipos de recursos e mídias que seriam disponibilizados (textos, vídeos, imagens, mapas conceituais), e foi feita a delimitação dos conteúdos, com o levantamento teórico de material impresso e de textos disponibilizados na web através de um storyboard como ilustrado na figura 2.

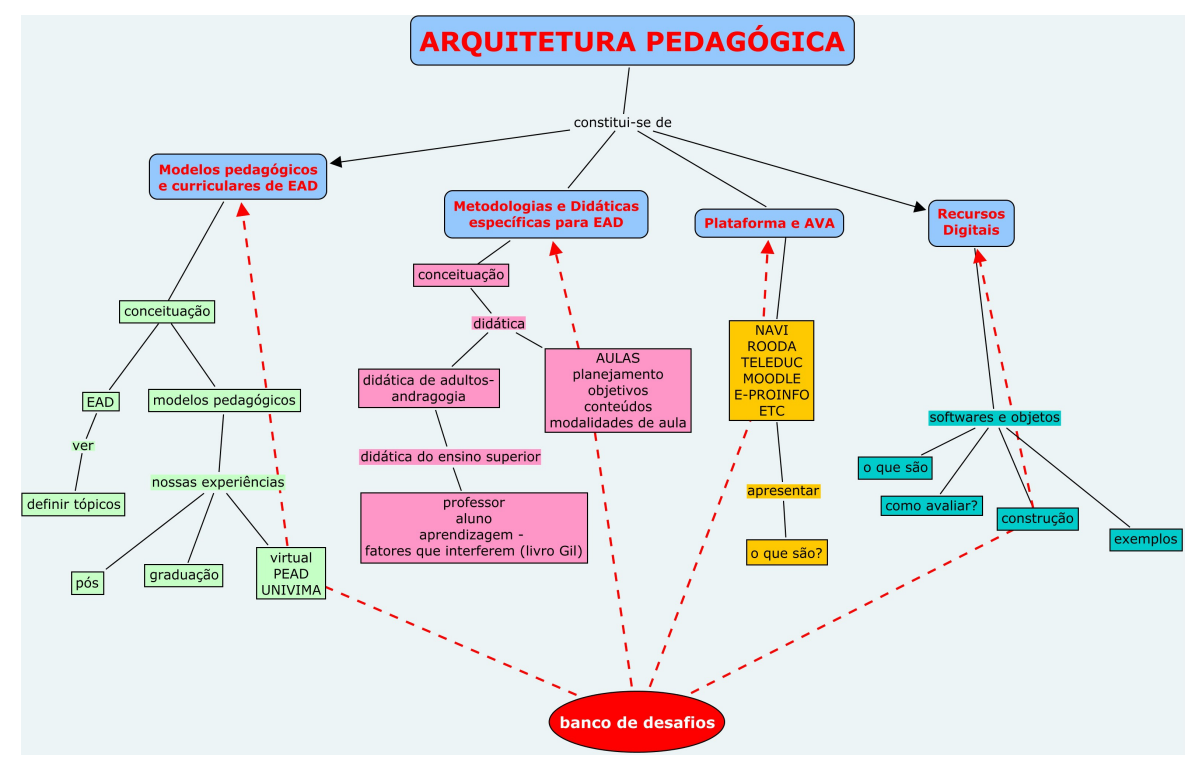

Figura 2: Storyborad do Objeto ARQUEAD

Para o desenho da interface, foram analisadas as definições do papel do design na elaboração de objetos de aprendizagem. A preocupação estava em tornar os conteúdos dinâmicos e integrados. Por isso, o design didático do objeto foi definido em função das intenções e funções pretendidas, identificando possíveis estratégias de aprendizagem, implementadas de forma dinâmica. Para a criação da interface, definiu-se pelo uso das ferramentas Flash, AutoCAD e Autodesk 3D Studio MAX de programação, para a elaboração dos primeiros protótipos do objeto até ser obtida a sua versão final. Destaca-se 
que estes softwares possuem ferramentas que possibilitam a utilização de animações e recursos interativos, sendo esta o interesse da equipe.

$\mathrm{Na}$ fase de implementação, foram desenvolvidos os primeiros protótipos do objeto ARQUEAD, conforme mostra a figura 3. Foram construídos três protótipos, com diferentes tipos de animação. O primeiro protótipo caracterizou-se por uma estrutura pedagógica linear, estática e de pouca interação, não atendendo a proposta do objeto. Era preciso colocar em prática os critérios de usabilidade para se chegar a uma interface convidativa a sua utilização.

No segundo protótipo, foram realizadas melhorias com a introdução de simulações em forma de vídeo e o uso de um personagem protagonista, representado por um "Professor". A estrutura com uso de animações foi considerada um avanço em termos de design de interação.
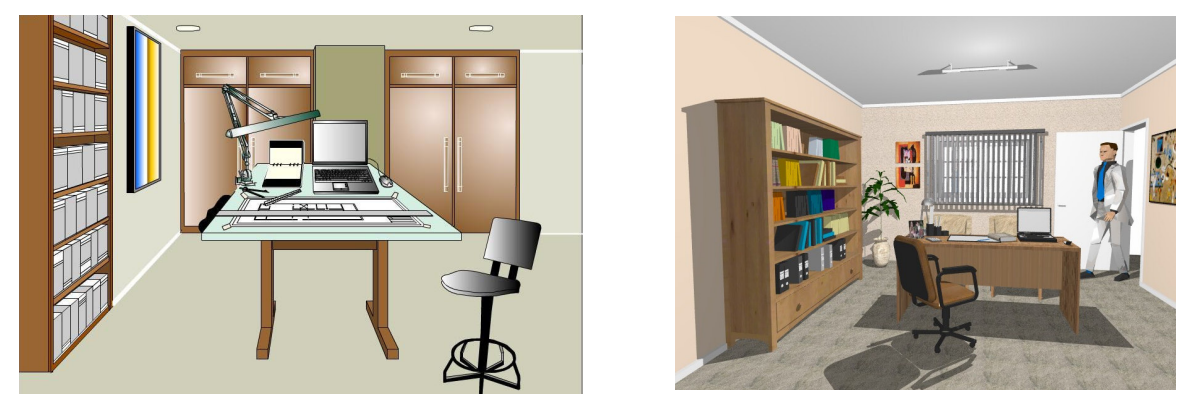

Figura 3: Protótipo I e II do ARQUEAD

$\mathrm{Na}$ terceira versão, apresentada na figura 4, foi alcançado o resultado almejado, com a elaboração de novos elementos baseados nos critérios de usabilidade e design pedagógico para o ARQUEAD. Foram construídas cenas sobre situações cotidianas vivenciadas por um docente que inicia suas atividades no contexto da EAD. Estas situações estão apresentadas em formato de animações, como em um filme. Acredita-se que, desta forma, é possibilitada uma maior interação entre o usuário e o objeto de aprendizagem, pela identificação proporcionada pelo personagem e suas ações.
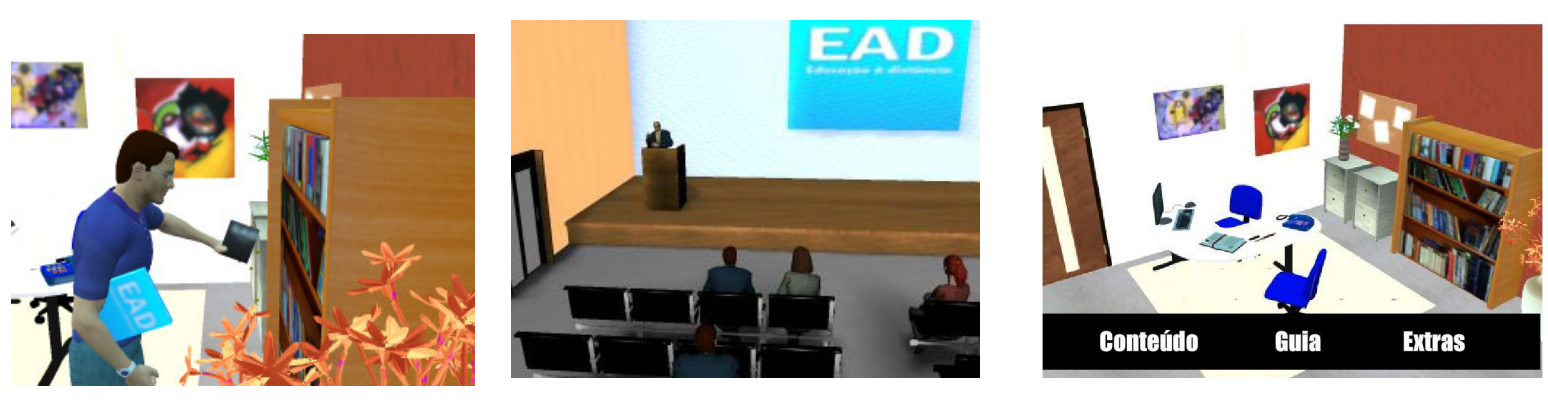

Figura 4: Cenas dos vídeos e tela inicial do ARQUEAD 
Assim, o ARQUEAD foi finalizado, abordando referenciais teóricos sobre os elementos que constituem uma Arquitetura Pedagógica, sendo estes: (1) fundamentação do planejamento/proposta pedagógica (aspectos organizacionais): onde estão incluídos os propósitos da aprendizagem, organização do tempo e do espaço e expectativas na relação da atuação dos participantes ou da organização social da classe, (2) conteúdo - materiais instrucionais e/ou recursos informáticos utilizados - objetos de aprendizagem, software e outras ferramentas; (3) atividades, interações, procedimentos de avaliação e a organização de todos esses elementos numa seqüência didática para a aprendizagem (aspectos metodológicos); (4) definição da plataforma de EAD e suas funcionalidades (aspectos tecnológicos).

Através das cenas, o personagem "Professor" passa por dificuldades semelhantes às enfrentadas no momento de se familiarizar com a EAD. Os desafios propostos ao usuário do objeto estão embasados em atividades para ajudar o personagem a resolver estas situações. Entre outros recursos que o objeto disponibiliza, está uma Biblioteca com textos e links interessantes acerca do tema, um Guia que traz sugestões para o professor sobre os recursos do ARQUEAD e suas possibilidades de uso, um Glossário, enfocando termos específicos do tema Arquiteturas Pedagógicas, e um material de Ajuda, para esclarecimentos sobre os recursos do objeto. A figura 4 ilustra ainda a página inicial do referido objeto. Logo, entende-se que, pelo conjunto de recursos utilizados no ARQUEAD, este objeto pode fornecer apontamentos relevantes, principalmente, aqueles referentes à didática da EAD.

A fase de avaliação consiste em testar o funcionamento do objeto, seu grau de adequação ao público-alvo e o nível de cumprimento dos objetivos. Foram realizados testes da própria equipe de desenvolvimento para acertar possíveis erros e imperfeições no objeto e, num segundo momento em um curso de extensão promovido pelo Núcleo de Tecnologia Digital aplicada à Educação (NUTED) da UFRGS. A partir dos dados coletados, foi possível observar se o objeto estava de acordo com características técnicas (tamanho do arquivo e programação), funcionais (animações e layout das telas) e didáticas (referenciais teóricos e desafios) que constavam nas suas etapas de construção.

\section{Validação do objeto de aprendizagem ARQUEAD em um curso de extensão}

O objeto ARQUEAD foi aplicado no curso de extensão, intitulado "Oficina de Arquiteturas Pedagógicas para EAD", destinado para professores e tutores atuantes em cursos da UFRGS. O curso teve carga horária total de 40 horas. Este foi desenvolvido pelo NUTED e ministrado por duas pesquisadoras do núcleo, participantes da equipe de construção deste objeto. O público foi composto por quinze participantes com experiência de atuação em cursos a distância.

O curso ocorreu em cinco encontros semanais, sendo quatro deles presenciais, com atividades desenvolvidas no decorrer da semana e um encontro totalmente a distância. Para a realização das atividades, foi utilizado o objeto de aprendizagem ARQUEAD integrado ao uso do ambiente ROODA. Para a publicação das tarefas e momentos de interação, foram utilizadas as funcionalidades: Aulas, Bate-Papo, Fórum, Diário de Bordo e Webfólio. Através desta plataforma os alunos tiveram a oportunidade de interagir de forma síncrona, assíncrona e na modalidade à distância. Foram abordadas temáticas referentes aos 
elementos constituintes de uma arquitetura pedagógica (AP), para uma melhor compreensão da sua construção. Durante as aulas presenciais foram discutidos os seguintes temas: Educação a Distância (EAD), Tecnologias da Informação e Comunicação (TICs), Objetos de Aprendizagem (OAs), Andragogia e Arquiteturas Pedagógicas (APs). Os alunos expuseram suas dúvidas e reflexões compreendendo a importância da construção das Arquiteturas Pedagógicas.

Destaca-se também que o curso foi aberto à comunidade em geral interessada em trabalhar com a EAD, mais especificadamente para professores que atuam nesta área.

Dentre os dados coletados, foram observados aspectos relevantes apontados pelos alunos para o desenvolvimento de uma aula em EAD. Neste sentido, foi realizada uma reflexão sobre as características acerca do planejamento pedagógico, com destaque para o papel do professor neste contexto. Compreende-se assim que o entendimento a respeito da concepção da prática pedagógica da EAD foi o primeiro passo para o desenvolvimento das APs.

Através da utilização do objeto de aprendizagem como material educativo, percebeuse que os alunos do curso consideraram o ARQUEAD como um recurso pedagógico que integra referencias teóricos e atividades voltadas ao estudo da aprendizagem na EAD. A partir do uso deste OA foi analisada a importância de contextualizar os recursos utilizados em uma aula com a temática, como um fator indispensável para garantir a qualidade do planejamento pedagógico.

Outro apontamento levantado tanto nas falas dos alunos como nos seus escritos foi a respeito do papel do professor na EAD e a necessidade de formação específica para atuar nessa modalidade. Neste debate foi discutido que, apesar de haver iniciativas governamentais que apóiam a formação continuada de professores e atividades em EAD, grande parte dos professores que estão atuando a distância não tiveram acesso a uma capacitação que os auxiliassem a compreender as necessidades e particularidades desta modalidade de ensino. A partir das discussões realizadas, constatou-se que o professor precisa desta formação a fim de compreender as diretrizes pedagógicas voltadas ao planejamento de uma aula EAD, o perfil a ser construído para o aluno virtual, além de instrumentalizá-los através do uso dos recursos digitais. Portanto, vislumbra-se a importância de haver investimentos na formação continuada de professores para o exercício da EAD.

Ressalta-se, como desafio maior vivenciado neste curso, a atividade voltada para a construção das Arquiteturas Pedagógicas e de seus elementos conforme está apresentada na figura 1. Neste momento, os alunos, em pequenos grupos, puderam dialogar com os pares, partindo dos conteúdos trabalhados e disponibilizados e as atividades desenvolvidas através do objeto. Quando estes começaram a criar suas APs, organizando suas idéias a partir da descrição dos seus elementos, logo perceberam que esta construção deve ser realizada por um professor em sua disciplina. Porém, chegou-se a um consenso da importância de todos os participantes da EAD (professores, monitores e alunos) de compreender como ocorre esta construção. Assim, foi iniciada uma reflexão acerca do papel do professor neste desenvolvimento, inclusive para apoiar as ações a serem exercidas pelo tutor e pelos alunos, e a constatação da existência de equívocos nos trabalhos realizados nesta área.

Com esta interação, foi possível refletir sobre a complexidade do desenvolvimento de uma AP. Os grupos de alunos construíram suas APs de acordo com as áreas de seu interesse, enfocando, na sua maioria, cursos na modalidade a distância dos quais 
participaram anteriormente, procurando outras alternativas de atividades e conteúdos que poderiam ser abordados nesses.

Percebeu-se com estas construções de APs, feitas pelos alunos, que os mesmos apropriaram-se dos conceitos abordados durante o curso e conseguiram colocá-los em prática. Foi oportunizado assim o entendimento da AP não somente como um sistema ou conjunto de estratégias, mas como um conjunto de elementos organizacionais, tecnológicos, metodológicos e instrucionais (Behar, 2009).

Logo, através das atividades trabalhadas no projeto piloto, foi possível ressaltar a necessidade de serem conhecidos o projeto pedagógico dos cursos e as orientações para a EAD da instituição, para a melhor adequação da construção da AP à sua proposta.

Concluindo com a análise do objeto, todos avaliaram de forma positiva o uso do ARQUEAD no curso. Os participantes relataram não terem experiência anterior com uso de um objeto de aprendizagem, mesmo alguns já tendo trabalhado em EAD. Desta forma, considera-se que o uso de OAs por professores ainda não é uma tarefa corrente.

Nesta perspectiva, pôde-se observar que os alunos puderam realizar algumas conexões teóricas através das temáticas trabalhadas partindo dos conteúdos propostos no ARQUEAD. Mais do que isso, acredita-se que puderam vivenciar a experiência da construção de uma arquitetura pedagógica. Também foram levantadas sugestões de aperfeiçoamento para o objeto de aprendizagem em questão, como a inserção de vídeos relativos ao assunto abordado.

\section{Considerações Finais}

Através do estudo apresentado, considera-se que o objeto de aprendizagem ARQUEAD oportunizou, como ferramenta de apoio, que os participantes do curso de extensão relatado pudessem vivenciar uma experiência de construção de Arquiteturas Pedagógicas. Acompanhar os alunos na construção das suas próprias APs contribuiu para importantes reflexões sobre as concepções do professor e sobre suas estratégias didáticas.

Constatou-se, assim, que na construção das arquiteturas pedagógicas o professor tem um papel indispensável, onde deve comprometer-se com as novas tecnologias, possibilitando assim meios e formas mais adequadas de ensinar e aprender. Neste contexto, o professor deve estar presente para desenvolver de forma eficaz seu papel neste novo espaço educativo. Portanto, é de extrema importância a continuidade de estudos nesta área para aprofundamento da temática.

Acredita-se que a pesquisa realizada através de um curso de extensão, permitiu transformações nas práticas de todos os sujeitos envolvidos através do engajamento destes nas questões de EAD e da necessidade de assumirem uma postura crítica frente aos novos aspectos que foram sendo trazidos.

Salienta-se ainda que recentemente o objeto ARQUEAD foi utilizado em outra experiência de validação com alunos dos cursos de pós-graduação em Educação e em Informática na Educação, sendo que neste momento estão sendo coletados os dados para comparar os resultados com o curso de extensão citado, a fim de obter uma segunda experiência para aperfeiçoá-lo para novos cursos e atividades.

Espera-se, desta forma, que o ARQUEAD possa ser mais uma ferramenta ao alcance de professores em formação ou não, alunos e demais usuários da web. Assim, este objeto pode vir a auxiliar na instrumentalização teórica e prática sobre sua temática, através de 


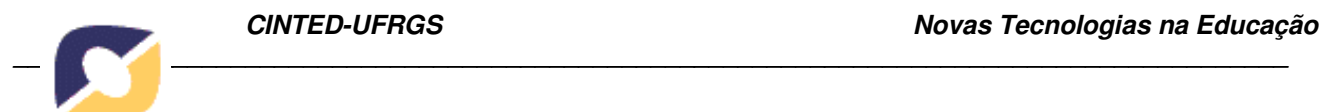

diferentes recursos tecnológicos, que podem ser empregados em diferentes campos de atuação.

\section{Referências Bibliográficas}

AMANTE, L; MORGADO, L. (2001). Metodologia de Concepção e Desenvolvimento de Aplicações Educativas: o caso dos materiais hipermedia. Revista Discursos: língua, cultura e sociedade, Lisboa, v. 3, n. especial, p. 27-44.

BEHAR, P.A. e colaboradores (2009). Modelos pedagógicos para a educação a distância. Porto Alegre: Artmed.

BEHAR, P.A.; PASSERINO, L., BERNARDI, M. (2007). Modelos Pedagógicos para Educação a Distância: pressupostos teóricos para a construção de objetos de aprendizagem. RENOTE. Revista Novas Tecnologias na Educação, v. 5, p. 25-38.

ZABALA, A. (1999). A prática educativa: como ensinar. Porto Alegre: Artes Médicas.

WILLEY, David A. (2002) Connecting learning objects to instructional design theory: A definition, a metaphor, and a taxionomy. Disponível em: http://reusability.org/read/chpters/wiley.doc. Acesso em 09 de Setembro de 2008. 